\title{
ARTICLE
}

\section{Comparison between the measurements by the fiber-optic gamma radiation sensors with the sensing probes of different height}

\author{
Sang Bin Lee, Jae Wook Kim, Rinah Kim and Joo Hyun Moon* \\ Department of nuclear \& Energy System Engineering, Dongguk University-Gyeongju, Gyeongju, Gyeongbuk, Rep. of Korea
}

\begin{abstract}
This study developed a fiber-optic radiation sensor (FORS) to make real-time measurement of gammaradiation at the nuclear facility decommissioned site. The FORS consisted of a sensing probe, a transmitting plastic optical fiber, a measuring device and a laptop computer. The sensing probe of the FORS was hexahedron form and fabricated using LYSO:Ce inorganic scintillator, mixture of epoxy and hardener as light guide, and aluminum foil as a reflector. Two sensing probes with different heights, $0.3 \mathrm{~mm}$ and $15 \mathrm{~mm}$, were prepared. The light transmitted through the plastic optical fiber was converted by the photomultiplier tube and amplified by an amplifier. A multi-channel analyzer (MCA) with the GENIE2000 program was used for the data acquisition and analysis. The FORSs were applied to measure a Co-60 disk source $(92.43 \mu \mathrm{Ci}, 2015.02)$. The measurements showed that the sensing probe with the height of $15 \mathrm{~mm}$ was better in terms of detection efficiency.
\end{abstract}

\section{Keywords: LYSO:Ce; fiber-optic sensor; inorganic scintillator; epoxy resin}

\section{Introduction}

There are many types of residual radiation at the nuclear facility decommissioned site. The main residual radionuclides are $\mathrm{Pu}-239, \mathrm{Pu}-242, \mathrm{Cs}-137, \mathrm{Sr}-90, \mathrm{Am}-$ 241, I-131, Ra-226, Co-60 and Th-232 [1]. Among these, the gamma emitters such as Cs-137 and Co-60 are important. For unlimited release or limited release of the decommissioned site, it should confirm that the residual radioactivity is less than the site release criteria. Compliance with the site release criteria is verified by analyzing statistically the radioactivity measurements using in-situ survey or sample analyses for the decommissioned site soil [2]. Measurement of radioactive contaminated soil at the site is time- and labor-intensive, irrespective of the measurement methods, because the site is spacious and the measurements are repetitive tasks. To improve this situation, therefore, a new instrument is required to measure the residual radiation in shorter time [3-5].

In general, a fiber-optic radiation sensor is composed of a scintillator, an optical fiber, and an optical measuring instrument [6]. The fiber-optic radiation sensor has a high spatial resolution and the advantage of being capable of remote measurement. It is not interfered by ambient temperature, pressure and electromagnetic waves. In addition, it can do real-time measurement [7-9].

This study developed the FORS for remote and real-

*Corresponding author. Email: jhmoon86@dongguk.ac.kr time measurements of gamma-radiation. The FORS system consisted of an inorganic scintillator, a mixture of epoxy resin and hardener, a plastic optical fiber and photomultiplier tube (PMT), an amplifier, a multichannel analyzer (MCA), a laptop computer equipped with a GENIE2000 program.

\section{Materials and methods}

The sensing probe consisted of an inorganic scintillator (LYSO), a light guide, and a plastic optical fiber. The inorganic scintillator was $(\mathrm{Lu}, \mathrm{Y})_{2} \mathrm{SiO}_{5}: \mathrm{Ce}$ (LYSO, Advanced Microwave Technology Solution Co., Ltd, Korea). As shown in Table 1, the LYSO:Ce inorganic scintillator has high density, high scintillation efficiency and a refractive index of 1.82, which is close to the refractive index of the optical fiber for light transmission [10]. Two sensing probes with different heights, $0.3 \mathrm{~mm}$ and $15 \mathrm{~mm}$ but the same length and width, were prepared; hexahedron type-1 (25 mm x 25 $\mathrm{mm} \times 0.3 \mathrm{~mm})$ and hexahedron type-2 $(25 \mathrm{~mm} \times 25 \mathrm{~mm}$ x $15 \mathrm{~mm}$ ). Figure 1 shows the two FORS sensing probes.

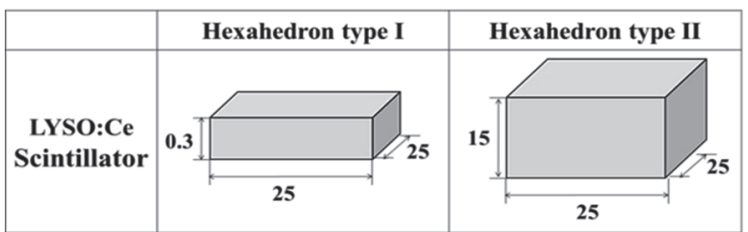

Figure 1. Cross-sectional view of the LYSO:Ce sensing probes (unit: $\mathrm{mm}$ ). 


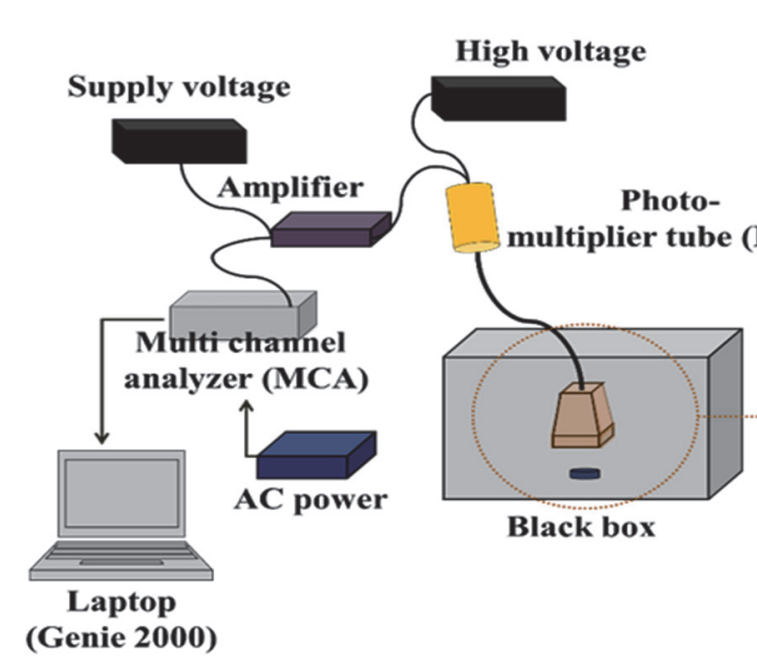

Figure 2. Experimental setup.

Table 1. Main characteristics of the inorganic LYSO:Ce Scintillator.

\begin{tabular}{ccccc}
\hline $\begin{array}{l}\text { Density } \\
\left(\mathrm{g} / \mathrm{cm}^{3}\right)\end{array}$ & $\begin{array}{l}\text { Wavelength } \\
\text { peak } \\
(\mathrm{nm})\end{array}$ & $\begin{array}{l}\text { Light yield } \\
(\%) \\
\text { Relative to } \\
\text { NaI:Tl }\end{array}$ & $\begin{array}{l}\text { EffectiveZ } \\
\text { Number }\end{array}$ & $\begin{array}{l}\text { Decay time } \\
(\mathrm{ns})\end{array}$ \\
\hline 7.20 & 420 & $73-75$ & 65 & 42 \\
\hline
\end{tabular}

This study used the light guide fabricated in the previous study [11]. The light guide was a mixture of an epoxy resin YD-128 (Kukdo, Korea) and a hardener D230 (Kukdo, Korea). The mixing ratio of the epoxy resin and the hardener was 5:1, which had been decided based on the test results in Table 2 . The numbers in columns of 'Transmittance' and 'Self-absorbance' of Table 2 are ranks of the mixtures having different mixing ratios. The higher is the number, the more favorable are characteristics of the mixture. Next, the light guide and the scintillator were wrapped with aluminum foil as a reflector, to minimize light leakage [12]. Figure 3 shows the sensing probe setup.

Table 2. Evaluation of the mixture according to the mixing ratio between YD-128 and D-230.

\begin{tabular}{lccc}
\hline $\begin{array}{l}\text { Mixing ratio } \\
\text { in grams } \\
\text { (YD-128: }\end{array}$ & $\begin{array}{l}\text { Transmittan } \\
\text { D-230) }\end{array}$ & $\begin{array}{l}\text { Self- } \\
\text { absorbance }\end{array}$ & Hardness \\
\hline $50.0: 10$ & 1 & 5 & Excellent \\
\hline $47.5: 12$ & 3 & 3 & Excellent \\
\hline $45.0: 14$ & 4 & 2 & Good \\
\hline $42.5: 16$ & 2 & 4 & Good \\
\hline $40.0: 18$ & 5 & 1 & Bad \\
\hline
\end{tabular}

The optical fiber used in this study was Edmund optics' plastic optical fiber (\#53-833). Its outer diameter and coating thickness were $3 \mathrm{~mm}$ and $0.05 \mathrm{~mm}$, respectively. The numerical aperture is 0.50 . Its core was made of Poly Methyl Methacrylate (PMMA) and its cladding was made of fluorine polymer (F-PMMA, fluorine poly methyl methacrylate) [13].

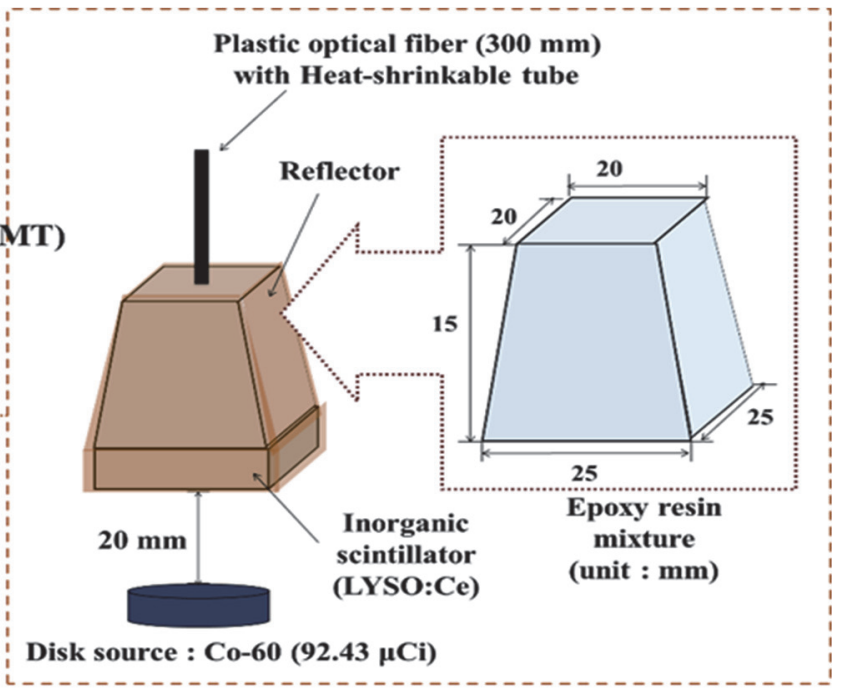

Sensing probe

Table 3. Properties of the plastic optical fiber.

\begin{tabular}{ccccc}
\hline $\begin{array}{l}\text { Outer } \\
\text { diameter } \\
(\mathrm{nm})\end{array}$ & $\begin{array}{l}\text { Core } \\
\text { diameter } \\
(\mathrm{nm})\end{array}$ & $\begin{array}{l}\text { Numerical } \\
\text { Aperture } \\
\mathrm{NA}\end{array}$ & $\begin{array}{l}\text { Attenuation } \\
(\mathrm{dB} / \mathrm{km}) \\
@ 6650 \mathrm{~nm}\end{array}$ & $\begin{array}{l}\text { Operating } \\
\text { Temperature } \\
\left({ }^{\circ} \mathrm{C}\right)\end{array}$ \\
\hline 3.0 & 2.95 & 0.50 & $150-300$ & -55 to +77 \\
\hline
\end{tabular}

Figure 2 shows the experimental setup. The photomultiplier tube (PMT, H9305-03, Hamamatsu photonic) had a maximum sensitive wavelength of about $450 \mathrm{~nm}$ and control the amplification of the signal by adjusting the supply voltage. The sensitive wavelength is compatible with the peak wavelength of LYSO:Ce, so it can correspond better with the light from the plastic optical fiber. The main characteristics of PMT were listed in Table 4. The current signal pre-amplified by PMT was amplified again by the amplifier (C7319, Hamamatsu photonic) and converted into a voltage signal. The voltage signal was transmitted to multichannel analyzer (MCA, model 2100, Canberra). The voltage signals were transferred to a computer and analyzed by the GENIE 2000 program.

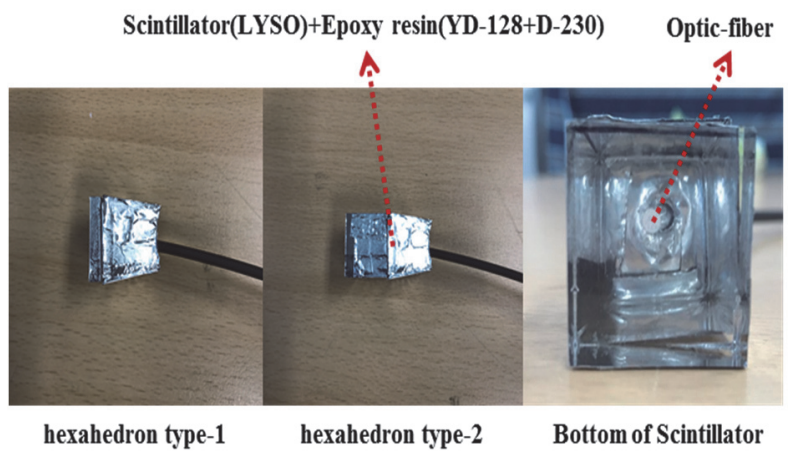

Figure 3. Sensing probes.

Table 4. Main characteristics of photomultiplier tube(PMT).

\begin{tabular}{cccc}
\hline $\begin{array}{c}\text { Wavelength } \\
\text { peak } \\
(\mathrm{nm})\end{array}$ & $\begin{array}{c}\text { Input } \\
\text { Voltage }\end{array}$ & $\begin{array}{c}\text { Operating } \\
\text { Temperature }\end{array}$ & $\begin{array}{c}\text { Time } \\
\text { Response } \\
\text { (ns) }\end{array}$ \\
\hline 450 & +11.5 to + & +5 to $+50^{\circ} \mathrm{C}$ & 1.4 \\
& $15.5 \mathrm{~V}$ & & \\
\hline
\end{tabular}


The FORSs were applied to measure gamma radiation from a Co-60 disk source $(92.43 \mu \mathrm{Ci}, 2015.02)$. The FORSs were installed in a dark room to minimize the influence by ambient light. For the purpose of comparison, measurements by using a commercial GM counter (GM214007, NEO) were performed in the same conditions.

\section{Result and discussion}

Figure 4 shows the measurements by the two FORSs. As shown in Figure 4, the total counts by the hexahedron type-2 FORS were much higher than those by the hexahedron type-1 FORS. It means that the thicker scintillator is, the more generated in the scintillator light is.

The total counts in Table 5 were the average of measurements by the FORSs. The total counts by the hexahedron type-1 FORS and the hexahedron type-2 FORS were 155266 (258.8 cps) and 204307.8 (340.5 cps) for 600 seconds, respectively. The total counts by the GM counter were 56,235.4 (93.7 cps). Because Co-60 emits beta and gamma radiations and the GM counter is much more sensitive for beta radiation than gamma radiation, the contribution fractions by beta and gamma radiation should be applied to the GM total counts, in order to compare the net gamma detection efficiencies by FORS and the GM counter. It was found that about 3\% of the total counts were from gamma ray in case of Co60 source. Applying this fraction, the gamma contribution of the GM total measurement was found. The FORSs were more efficient than the commercial GM counter for gamma-ray detection, as shown in Table 5.

Before the measurements, the background was measured by the FORS. To determine if net radioactivity statistically different from the background was present, the critical level $\left(L_{c}\right)$ was applied [14] :

$$
L_{C} \cong 2.33 \sqrt{n_{b}}
$$

where $n_{b}$ presents total background counts. As shown in Table 5, the total counts were larger than the sum of the critical value and the background counts. Therefore, it seems that the two FORSs could measure gamma radiation distinguishable from the background radiation.

This study developed a fiber-optic radiation sensor consisting of LYSO:Ce inorganic scintillator, plastic optical fiber, PMT, amplifier, MCA and GENIE2000 program for real-time measurement of gamma radiation at the nuclear facility decommissioned site. From the measurements of the gamma radiation from Co-60, the FORSs were able to measure the gamma radiation distinguishable from the background radiation. And the comparison between measurements by the two FORSs showed that the sensing probe with the height of $15 \mathrm{~mm}$ was better in terms of detection efficiency.

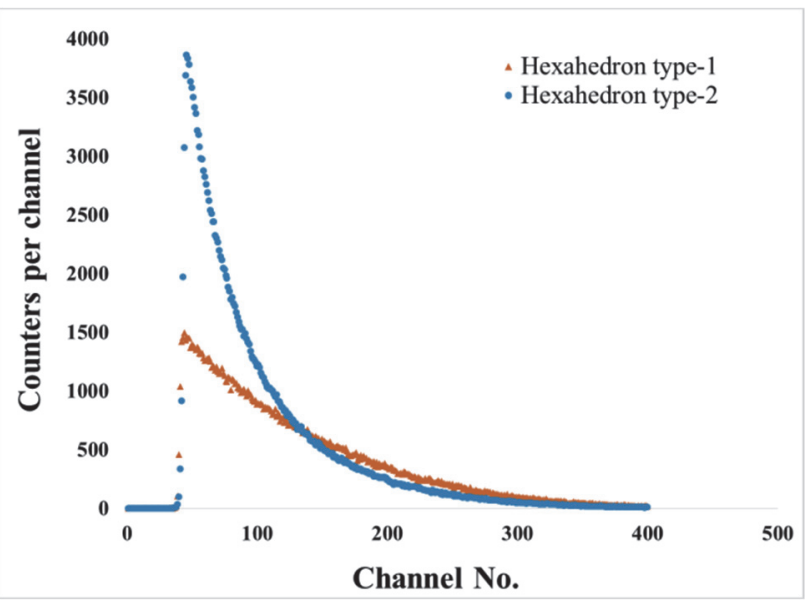

Figure 4. Mesurements by the two FORSs.

Table 5. Comparison between the measurements by a commercial detector and the two FORSs.

\begin{tabular}{cccc}
\hline Detector & Backgrounds & $\begin{array}{c}\text { Critical } \\
\text { level }\end{array}$ & $\begin{array}{c}\text { Total } \\
\text { counts }\end{array}$ \\
\hline $\begin{array}{c}\text { Commercial } \\
\text { detector } \\
\text { (GM } \\
\text { counter) }\end{array}$ & $* 13.7$ & 49.8 & $* 56,235.4$ \\
\hline $\begin{array}{c}\text { FORS } \\
\text { hexahedron-1 }\end{array}$ & 21.9 & 10.9 & 155,266 \\
\hline $\begin{array}{c}\text { FORS } \\
\text { hexahedron-2 }\end{array}$ & 65.8 & 18.9 & $204,307.8$ \\
\hline
\end{tabular}

$*$ total counts $\times$ countribution fraction by gamma-ray.

\section{Acknowledgements}

This study was supported by a National Research Foundation of Korea(NRF) grant funded by the Korea government is Ministry of Science, ICT and Future Planning (MSIP, Research Project No. 2012M2B2B1055499).

\section{References}

[1] L.E. Boing, Introduction to Decommissioning, Argone National Laboratory (2013).

[2] Korea Atomic Energy Research Institute, Development of $D D \& R$ Technology for Nuclear Facilities- Development of Nuclear Environment Purification Technology, 5 (3) (2012), pp. 17-18.

[3] U.S Nuclear Regulatory Commission, Nureg-1575, Rev.1 (2001)

[4] A.M. Huffert, R.A. Meck and K.M. Miller, NUREG-1501, (1994)

[5] Nuclear Energy Agency, NEA No. 6186(2006).

[6] A.S. Beddar, T.J. Kinsella, A. Ikhlef and C.H. Sibata, A miniature 'Scintillator-Fiberoptic-PMT' detector system for the dosimetry of small fields in stereotactic radiosurgery, IEEE Trans. Nucl. Sci. 48 (2001), pp. 924-928.

[7] S.H. Shin, K.W. Jang, W.J. Yoo, J.K. Seo, B. Lee, J.H. Moon, S. Kim and B.G. Park, Measurement of relative depth dose rates for a brachytherapy Ir-192 
source using and organic scintillator fiber-optic radiation sensor, J. Kor. Sensors Soc. 17 (6) (2008), pp. 462-469.

[8] K.W. Jang, D.H. Cho, S.H. Shin, W.J. Yoo, J.H. Jeon, B. Lee, J.H. Moon and B.G. Park, Fabrication and characterization of a one dimensional fiber-optic dosimeter for electron beam therapy dosimetry, J. Kor. Sensors Soc. 19 (4) (2008), pp. 285-290.

[9] K.W. Jang, D.H. Cho. W.J. Yoo, J.K. Seo, J.Y. Heo, B. Lee, S.H. Shin, B.G. Park and S. Kim, Measurement of relative dose irradiated from a Co60 source using a scintillating fiber-optic dosimeter, J. Kor. Sensor Soc. 19 (1) (2010), pp. 52-57.

[10]K.T. Han, W.J. Yoo, S.H. Shin, D.Y. Jeon, J.Y. Park, B.G. Park and B.S. Lee, Development of fiber-optic radiation sensor using LYSO scintillator for gamma-ray spectroscopy, Journal of Sensor Science and Technology 21 (4) (2012), pp. 287-292.

[11]C.H. Park and J.H. Moon, Development and characterization of the integrated fiber-optic sensor for remote detection of alpha radiation, Journal of the Korean Physical Society 63 (9) (2013), pp. 1720-1723.

[12]H.Y. Joo, R. Kim and J.H. Moon, Radioactivity measurement of radioactive contaminated soil using fiber-optic radiation sensor, Journal of the Korean Physical Society 68 (2016), pp.1287-1290.

[13]C.H. Park, Development and demonstration of auxiliary surveillance system for gamma radiation level measurement of spent fuel storage tank, (2015).

[14]J.K. Lee, Principles of radiation protection, Korean Association for Radiation Application, (2016). 